\title{
PAPER
}

\section{Neuropsychological and quality of life outcomes 12 months after unilateral thalamic stimulation for essential tremor}

\author{
J A Fields, A I Tröster, S P Woods, C I Higginson, S B Wilkinson, K E Lyons, W C Koller, \\ R Pahwa
}

See end of article for

authors' affiliations

J Neurol Neurosurg Psychiatry 2003;74:305-311

....................

Correspondence to:

Dr A I Tröster, Department

of Psychiatry and

Behavioral Sciences,

University of Washington

School of Medicine,

1959 NE Pacific Street, BB

1529, Box 356560,

Seattle, WA 98195-6560,

USA;

atroster@u.washington.edu

Received

10 January 2002

Accepted in final revised

form

20 November 2002

\begin{abstract}
Objectives: To evaluate the one year cognitive, mood state, and quality of life (QoL) outcomes of unilateral thalamic deep brain stimulation (DBS) for essential tremor (ET).

Methods: 40 patients diagnosed with ET completed comprehensive neuropsychological assessments about one month before and three and 12 months after DBS electrode implantation. Data were subjected to multivariate analyses, and significant results were further analysed using univariate techniques.

Results: Analyses revealed statistically significant improvements on a cognitive screening measure and in aspects of fine visuomotor and visuoperceptual functions, verbal memory, mood state, and QoL. No group-wise declines in cognition were observed, but more patients showed declines than improvements on language and visual memory tests. Semantic verbal fluency declined significantly in four (10\%) of the patients. In these four patients, diminished lexical verbal fluency was present at baseline.

Conclusion: Cognitive, mood, and QoL outcomes after one year of DBS for ET are favourable; there were no overall deleterious effects on cognition, and DBS was accompanied by a significant reduction in anxiety and improvements in quality of life. However, preoperative verbal fluency diminution may predispose to further fluency declines after DBS.
\end{abstract}

E ssential tremor (ET), one of the most common movement disorders, renders a disabling, non-uniform, bilateral effect primarily on the upper limbs, although the lower limbs, head, face, voice, and trunk may be affected to a lesser extent. ${ }^{1}$ Despite the high prevalence of this disorder (estimates range from $1 \%$ to $22 \%$ of the elderly population ${ }^{2}$ ), neither its pathophysiology nor its functional mechanisms are well understood. There is debate about whether the tremors of ET and Parkinson's disease (PD) are associated, ${ }^{2}$ and whether PD and ET are different manifestations of the same disorder. ${ }^{3}$ From a cognitive standpoint, recent studies of ET reveal patterns of cognitive changes that qualitatively overlap those seen in PD, but are more circumscribed and less severe. ${ }^{4-7}$

With the recognised success of deep brain stimulation (DBS) in relieving parkinsonian and essential tremor, an important issue is whether the benefit of regaining a degree of motor control (that cannot be pre-determined in an individual patient) outweighs possible cognitive morbidity or a decline in quality of life (QoL). Studies of PD permit the tentative conclusion that cognitive morbidity and QoL risks are minimal after unilateral thalamic DBS..$^{8-11}$ A priori, it might be assumed that the same would hold true for ET, but empirical evidence is limited.

Short-term results of thalamic DBS for ET have yielded variable findings regarding the nature and extent of cognitive changes after surgery. For example, no significant effect on cognition was reported by Lucas et al $^{12}$ in a single case study. Negligible cognitive morbidity has been observed in two other studies. Blond et $a l^{13}$ observed a transient slowing of information processing in one of four ET patients. In a study of 40 patients evaluated three months after surgery, Tröster et $a l^{14}$ found declines in lexical verbal fluency (but gains in some measures of attention, visual perception, and memory), and reported significant improvements in QoL. There was no significant mood disturbance (which can occur after DBS in $\mathrm{PD}^{15}$ ). Because longer term effects of thalamic DBS in ET are unknown, this study was undertaken to consider: (1) cognitive and QoL functioning after stimulation over an extended period of time, namely, 12 months, and (2) the course of previously reported changes, specifically, whether gains observed at three months were maintained, and whether deficits had resolved. An ancillary purpose of the study was to learn whether the few anticipated group-wise neurobehavioural changes after DBS might hide the existence of subgroups of patients who experience marked declines or improvements. To this end, frequency of changes exceeding two standard deviations in test scores were tabulated.

\section{METHODS}

\section{Participants}

Thirty five patients underwent DBS implantation in the left ventrointermediate (Vim) nucleus of the thalamus, five in the right. Table 1 shows participants' demographic and disease characteristics. All 40 participants in this study who were diagnosed with ET exhibited a postural and/or kinetic tremor (without additional neurological signs) that significantly disrupted their activities of daily living and was inadequately controlled by drugs for at least three months before surgery. Patients were considered DBS candidates unless they had any of the following: (1) prior thalamotomy; (2) other intracranial CNS disease (except possible PD in two cases); (3) medical conditions requiring repeated MRI; (4) cardiac pacemaker; (5) unstable medical problems. Additionally, if baseline neuropsychological evaluation revealed a major psychiatric disturbance or dementia, the patient was no longer considered a surgical candidate and was excluded from the study. Of 59

Abbreviations: ET, essential tremor; DBS, deep brain stimulation; QoL, quality of life; PD, Parkinson's disease 
Table 1 Key demographic and disease variables, pre/post intervals, stimulator settings, and tremor scores (mean (SD))

\begin{tabular}{|c|c|c|c|c|c|}
\hline \multicolumn{6}{|c|}{ Key variable (baseline) } \\
\hline \multicolumn{3}{|l|}{ Number } & \multicolumn{3}{|l|}{40} \\
\hline \multicolumn{3}{|l|}{ Age } & \multicolumn{3}{|l|}{$71.70(8.84)$} \\
\hline \multicolumn{3}{|l|}{ Education } & \multicolumn{3}{|l|}{$14.12(2.72)$} \\
\hline \multicolumn{3}{|l|}{ Sex } & \multicolumn{3}{|l|}{$23 \mathrm{M} / 17 \mathrm{~F}$} \\
\hline \multicolumn{3}{|l|}{ Handedness } & \multicolumn{3}{|l|}{$37 \mathrm{R} / 3 \mathrm{~L}$} \\
\hline \multicolumn{3}{|c|}{ Estimated Verbal IQ } & \multicolumn{3}{|l|}{$102.32(9.59)$} \\
\hline \multicolumn{3}{|c|}{ Dementia Rating Scale Total Score (/144) } & \multicolumn{3}{|l|}{$129.87(8.84)$} \\
\hline \multicolumn{3}{|c|}{ Beck Depression Inventory Total Score (/63) } & \multicolumn{3}{|l|}{$5.95(4.86)$} \\
\hline \multicolumn{3}{|c|}{ Beck Anxiety Inventory Total Score (/63) } & \multicolumn{3}{|l|}{$8.43(5.76)$} \\
\hline \multicolumn{3}{|c|}{ Age at symptom onset } & \multicolumn{3}{|l|}{$39.73(16.87)$} \\
\hline \multicolumn{3}{|c|}{ Disease duration (from diagnosis) } & \multicolumn{3}{|l|}{$18.14(1288)$} \\
\hline \multicolumn{6}{|c|}{ Fahn-Tolosa-Marin Tremor Rating Scale (/84, Items 1-10) 19.35 (6.85) } \\
\hline \multicolumn{6}{|c|}{ Neuropsychological (NP) assessment/surgery intervals (months) } \\
\hline Baseline NP to s & & $1.05(1.53)$ & & & \\
\hline Surgery to first $\mathrm{p}$ & & $3.26(0.94)$ & \multirow{2}{*}{\multicolumn{2}{|c|}{$\begin{array}{l}\text { Surgery to second post-NP } \\
\text { First post-NP to second post-NP }\end{array}$}} & $11.97(0.88)$ \\
\hline Baseline NP to $f$ & ost-NP & $4.30(1.74)$ & & & $8.71(1.29)$ \\
\hline \multicolumn{6}{|c|}{ Stimulation parameters at 3 and 12 months } \\
\hline \multirow{2}{*}{\multicolumn{2}{|c|}{ Side of surgery }} & 35 left, 5 right & \multirow{4}{*}{ Amplitude (V) } & & \\
\hline & & 3 months & & & 12 months \\
\hline \multirow{2}{*}{ Amplitude (V) } & Left & $3.40(0.60)$ & & Left & $3.18(0.53)$ \\
\hline & Right & $3.24(0.75)$ & & Right & $3.24(0.75)$ \\
\hline \multirow{2}{*}{ Frequency $(\mathrm{Hz})$} & Left & $147.14(25.62)$ & Frequency $(\mathrm{Hz})$ & Left & $150.57(25.72)$ \\
\hline & Right & $153.00(11.51)$ & & Right & $155.00(13.69)$ \\
\hline Pulse width ( $\mu$ s) & Left & $89.14(23.56)$ & Pulse width ( $\mu$ ) & Left & $100.29(32.49)$ \\
\hline & Right & $84.00(25.10)$ & & Right & $84.00(25.10)$ \\
\hline Tremor scores at & nd $12 n$ & & & & \\
\hline & & 3 months & & & 12 months \\
\hline Off stimulation & & $17.00(6.07)$ & Off stimulation & & $17.62(7.12)$ \\
\hline On stimulation & & $8.45(4.25)$ & On stimulation & & $8.45(4.13)$ \\
\hline
\end{tabular}

patients who presented for post-surgical follow up, 40 completed both three and 12 month neuropsychological follow up; three additional patients had 12 month but not three month follow up and were excluded from analyses. Those who only came for three month follow up $(n=16)$ did not differ from those who also came for 12 month follow up $(n=40)$ on any key demographic, disease, or neuropsychological test variables at three month evaluation. Thirty two of the patients participating in this study overlap with those reported by Tröster and colleagues. ${ }^{14}$ Mean scores reported in the previous sample at three months did not differ from the current sample's three month scores on any of the outcome measures (all $\mathrm{p}>0.05)$.

Participants continued the use of their tremor medication, if applicable, throughout motor and cognitive evaluations. Table 2 denotes the number of patients taking drugs for control of tremor, ${ }^{16}{ }^{17}$ and for anxiety and depression. Two patients with possible coexisting PD and ET were also taking levodopa and/or dopamine agonists, but only one continued to do so at 12 month follow up. These patients' scores did not differ from those of the rest of the sample on any outcome measures (all $\mathrm{p}>0.05)$ and were therefore included in the analyses. One other patient included in the study was taking donepezil at 12 month evaluation (even though memory scores were comparable to those at three months and there was no objective neuropsychological evidence of a dementing process in this patient).

\section{Motor examination}

The same neurologist (RP), experienced and specialising in the evaluation and treatment of movement disorders, completed all the motor examinations, including the FahnTolosa-Marin tremor rating scale. ${ }^{18}$ Items $1-10$ of this 21 item inventory were used to derive a motor score of 0 to 84 based on a 4 point scale for each item $(0=$ normal $)$, with several questions including multiple ratings to account for both resting and postural tremor in relevant body parts. Items related to drawing, pouring, speaking, and activities of daily living were not included because activities of daily living are covered in the QoL measures (mPDQ and SIP) and the neuropsychological battery evaluates verbal fluency, as well as fine visuomotor coordination and dexterity.

\section{Neuropsychological assessment}

Baseline neuropsychological evaluations were conducted about one month before surgery. Post-surgical assessments were conducted about three and 12 months after unilateral thalamic DBS implantation. The neuropsychological battery was constructed to assess a broad array of functional domains

Table 2 Tremor, depression, and anxiety medications

\begin{tabular}{llll}
\hline & Baseline & $\begin{array}{l}\text { Three months } \\
\text { after surgery }\end{array}$ & $\begin{array}{l}\text { Twelve months } \\
\text { after surgery }\end{array}$ \\
\hline Propranolol (Inderal) & 15 & 13 & 12 \\
Primidone (Mysoline) & 19 & 15 & 9 \\
Metoprolol (Lopressor) & 2 & 1 & 1 \\
Nadolol (Corgard) & 2 & 2 & 2 \\
Clonazepam (Klonopin) & 2 & 2 & 1 \\
Atenolol (Tenormin) & 0 & 0 & 1 \\
Gabapentin (Neurontin) & 1 & 1 & 0 \\
Topiramate (Topamax) & 0 & 0 & 1 \\
Acetazolamide (Diamox) & 1 & 0 & 0 \\
Fluoxetine (Prozac) & 0 & 1 & 0 \\
Sertraline (Zoloft) & 1 & 1 & 1 \\
Paroxetine (Paxil) & 1 & 2 & 1 \\
Imipramine (Tofranil) & 1 & 1 & 0 \\
Lorazepam (Ativan) & 3 & 2 & 3 \\
Diazepam (Valium) & 3 & 3 & 2 \\
Clorazepate (Tranxene) & 1 & 0 & 1 \\
Hydroxyzine (various) & 1 & 1 & 1 \\
Temazepam (Restoril) & 0 & 0 & 1 \\
\hline
\end{tabular}


Table 3 Neurocognitive test scores at baseline, three, and 12 months after surgery (mean/SD) and number of patients displaying test score changes of two or more standard deviations from three to 12 months and baseline to 12 months

\begin{tabular}{|c|c|c|c|c|c|c|c|}
\hline & \multirow[b]{3}{*}{ Baseline } & \multirow[b]{3}{*}{$\begin{array}{l}\text { Three months } \\
\text { after surgery }\end{array}$} & \multirow{3}{*}{$\begin{array}{l}\text { Twelve months } \\
\text { after surgery }\end{array}$} & \multirow{2}{*}{\multicolumn{2}{|c|}{$\begin{array}{l}\text { Improvement } \\
>2 \mathrm{SD}\end{array}$}} & \multirow{2}{*}{\multicolumn{2}{|c|}{$\begin{array}{l}\text { Decline } \\
>2 \mathrm{SD}\end{array}$}} \\
\hline & & & & & & & \\
\hline & & & & $3-12$ & B-12 & $3-12$ & B-12 \\
\hline \multicolumn{8}{|l|}{ Cognitive screening $(n=40)$} \\
\hline \multicolumn{8}{|l|}{ Mattis Dementia Rating Scale } \\
\hline Attention (/37) & $34.80(2.14)$ & $35.20(1.67)$ & $34.63(2.54)$ & 4 & 2 & 4 & 2 \\
\hline Initiation/Perseveration (37) & $33.75(3.75)$ & $34.87(3.57)$ & $34.85(3.75)$ & 3 & 6 & 2 & 2 \\
\hline Construction $(/ 6)^{\dagger \neq}$ & $4.40(2.13)$ & $5.55(0.85)$ & $5.57(1.11)$ & 4 & 14 & 4 & 1 \\
\hline Conceptualisation $(/ 39)^{\S}$ & $33.95(3.53)$ & $33.60(3.48)$ & $34.82(3.35)$ & 5 & 2 & 0 & 0 \\
\hline Memory (/25) & $22.92(1.70)$ & $23.38(1.64)$ & $23.23(2.63)$ & 1 & 0 & 2 & 1 \\
\hline \multicolumn{8}{|l|}{ Simple attention $(n=37)$} \\
\hline \multicolumn{8}{|l|}{ Wechsler Memory Scale-Revised } \\
\hline Mental control (6) & $5.00(1.08)$ & $5.05(1.15)$ & $5.08(1.30)$ & 1 & 0 & 1 & 1 \\
\hline Digit span forward (/12) & $7.70(1.97)$ & $7.97(1.94)$ & $8.03(2.17)$ & 0 & 0 & 1 & 0 \\
\hline Digit span backward (/12) & $5.57(1.80)$ & $5.22(1.69)$ & $5.62(1.93)$ & 1 & 0 & 0 & 0 \\
\hline Visual span forward (/14) & $7.73(1.64)$ & $8.05(1.72)$ & 7.95 (1.99) & 2 & 2 & 4 & 1 \\
\hline Visual span backward (/12) & $6.70(1.58)$ & $7.38(1.64)$ & $7.22(1.75)$ & 0 & 2 & 0 & 0 \\
\hline \multicolumn{8}{|l|}{ Complex attention $(n=30)$} \\
\hline Brief Test of Attention (/20) & $13.23(4.00)$ & $12.97(4.60)$ & $13.33(4.03)$ & 1 & 1 & 0 & 0 \\
\hline \multicolumn{8}{|c|}{ Stroop Neuropsychological Screening Test } \\
\hline Colour (/112) & $111.83(0.46)$ & $111.87(0.35)$ & $109.13(15.14)$ & 3 & 3 & 3 & 3 \\
\hline Colour-word (/112) & $73.67(23.85)$ & $75.67(24.27)$ & $74.97(26.14)$ & 0 & 1 & 0 & 0 \\
\hline \multicolumn{8}{|l|}{ Executive function $(n=32)$} \\
\hline \multicolumn{8}{|l|}{ Wisconsin Card Sorting Test } \\
\hline Categories (/6) & $4.22(1.96)$ & $4.09(2.05)$ & $4.44(1.97)$ & 1 & 1 & 0 & 1 \\
\hline Trials to first category $(\max 128)^{*}$ & $23.00(31.09)$ & $22.50(29.79)$ & $20.12(22.90)$ & 1 & 2 & 2 & 2 \\
\hline Perseverative responses* & $29.16(27.10)$ & $26.62(21.51)$ & $27.59(23.25)$ & 0 & 2 & 1 & 1 \\
\hline Failure to maintain set ${ }^{\star}$ & $1.03(1.20)$ & $1.44(1.41)$ & $0.91(1.30)$ & 6 & 4 & 2 & 1 \\
\hline \multicolumn{8}{|l|}{ Cognitive Estimation Test } \\
\hline $\begin{array}{l}\text { Deviation Score }(/ 10)^{*} \\
\text { Language }(n=40)\end{array}$ & $4.22(1.81)$ & $4.31(1.96)$ & $4.06(1.83)$ & 1 & 1 & 1 & 1 \\
\hline \multicolumn{8}{|l|}{ Semantic (category) fluency } \\
\hline (z score) & $-0.71(1.00)$ & $-0.75(1.09)$ & $-0.76(1.13)$ & 2 & 1 & 0 & 4 \\
\hline (raw score) & $14.22(4.86)$ & $14.03(4.66)$ & $12.98(3.79)$ & & & & \\
\hline \multicolumn{8}{|l|}{ Lexical (letter) fluency } \\
\hline (z score) & $-0.99(0.83)$ & $-1.12(0.85)$ & $-1.18(1.01)$ & 0 & 0 & 0 & 0 \\
\hline (raw score) & $30.38(9.96)$ & $28.40(10.23)$ & $28.10(12.44)$ & & & & \\
\hline Boston Naming Test (/60) & $51.70(7.56)$ & $51.43(10.53)$ & $53.53(5.41)$ & 1 & 2 & 0 & 0 \\
\hline \multicolumn{8}{|l|}{ Fine visuomotor coordination ( $n=29$ ) } \\
\hline Grooved pegboard & & & & & & & \\
\hline Dominant hand $(t \text { score })^{\dagger}$ ‡ & $26.41(8.97)$ & $34.00(8.20)$ & $32.10(8.06)$ & 0 & 2 & 0 & 0 \\
\hline Non-dominant hand ( $t$ score) & $30.90(10.50)$ & $31.52(10.17)$ & $31.00(9.72)$ & 0 & 0 & 1 & 1 \\
\hline Visuoperception (n=34) & & & & & & & \\
\hline Benton Facial Recognition (/54) & $43.53(5.73)$ & $45.00(3.93)$ & $44.18(4.44)$ & 1 & 2 & 2 & 0 \\
\hline $\begin{array}{l}\text { Hooper Visual Organisation Test }(/ 30)^{\dagger} \neq \\
\text { Visual memory }(n=34)\end{array}$ & $24.03(3.61)$ & $25.26(2.05)$ & $25.59(3.02)$ & 0 & 0 & 0 & 0 \\
\hline Wechsler Memory Scale-Revised & & & & & & & \\
\hline Figural memory $(/ 10)$ & $6.32(1.39)$ & $6.76(1.60)$ & $6.18(1.36)$ & 1 & 0 & 2 & 2 \\
\hline Verbal memory $(n=35)$ & & & & & & & \\
\hline California Verbal Learning Test & & & & & & & \\
\hline Total immediate (trials 1-5) & & & & & & & \\
\hline$(t \text { score })^{\ddagger} \S$ & $42.89(12.13)$ & 43.54 (10.79) & $48.43(12.17)$ & 2 & 2 & 0 & 0 \\
\hline Short delay free recall $(/ 16)^{\ddagger}$ & $7.77(2.82)$ & $8.31(3.27)$ & $8.86(3.00)$ & 6 & 2 & 3 & 0 \\
\hline Long delay free recall $(/ 16)^{\ddagger}$ & $8.23(3.27)$ & $9.06(3.07)$ & 9.43 (3.01) & 1 & 6 & 1 & 0 \\
\hline Recognition hits $(/ 16)^{t \ddagger}$ & $13.77(1.88)$ & $14.77(1.06)$ & $14.86(1.14)$ & 0 & 5 & 1 & 0 \\
\hline Wechsler Memory Scale-Revised & & & & & & & \\
\hline Logical memory-immediate (/50) & $22.77(7.20)$ & $23.74(7.43)$ & $24.66(6.23)$ & 0 & 0 & 0 & 0 \\
\hline Logical memory-delayed $(/ 50)^{\ddagger}$ & $17.09(7.36)$ & $20.23(9.01)$ & $20.97(7.10)$ & 0 & 0 & 0 & 0 \\
\hline
\end{tabular}

and includes measures of cognitive screening, attention and executive functions, memory, language, visuoperceptual skills, mood state, and QoL. Cognitive tests were selected to minimise motor demands. Alternate test forms were used for the verbal fluency tasks during pre-surgical and post-surgical assessments.

Quality of life was assessed with both disease specific and generic measures. The Parkinson's Disease Questionnaire-39 was modified (mPDQ) for ET simply by replacing all occurrences of "Parkinson's disease" with "essential tremor." The PDQ-39 contains 39 items that ask participants how often during the past month tremor has caused difficulty in eight domains of functioning (see table 5). The Sickness Impact
Profile, a generic QoL instrument containing items in 12 categories of physical and psychosocial functioning, asks patients to mark the items of difficulty that apply to them (see table 5). For both instruments, scores are recorded as percentages, where a higher percentage represents a greater amount of difficulty and/or dissatisfaction with function.

Because of time constraints and scheduling conflicts (many patients lived out of the greater metropolitan area), some participants were not able to complete the entire test battery. At the time of postoperative assessment, neuropsychologists and technicians were blind to participants' possible operative complications, tremor ratings, stimulation parameters, and preoperative test scores. 


\section{Surgical procedure}

The surgical procedure used is described in detail elsewhere. ${ }^{19}{ }^{20}$ In brief, cranial CT and stereotactic techniques were used to target the VIM nucleus contralateral to the side of the body chosen for treatment (that is, dominant hand in all but two patients whose non-dominant side symptoms were deemed to be more disabling). A quadripolar DBS electrode (model 3382; Medtronic, Minneapolis, MN) was positioned at the target site where intraoperative stimulation at the lowest voltage resulted in good tremor control, transient paresthaesias, and no gross speech deficits. Next, a subcutaneous pulse generator was placed in the subclavicular region and connected to an electrode lead. Contact selection and stimulation parameter programming were achieved after patient recovery and were adjusted on an outpatient basis.

\section{Data analyses}

To investigate whether or not neurobehavioural status was comparable across the three assessment time points, neuropsychological tests were firstly, for conceptual clarity, grouped according to the broad construct measured (for example, language; see table 3 ). The several outcome variables within each domain were then subjected to doubly multivariate (that is, repeated measures multivariate) analyses of variance using the three time points as the multivariately handled, within subjects factor and the several test scores in the domain as dependent variables. This approach to analysis represents one that permits one to conceptually identify the variate created in the analysis (for example, corresponding to a functional domain, such as language) while simultaneously reducing the number of analyses required and, consequently, the probability of type I error. Only when multivariate analyses yielded a significant result were individual test score means within that domain (for example, attention) compared by univariate repeated measures analysis of variance. The multivariate statistic required to be significant before follow up univariate analyses were conducted is the $F$ value associated with Wilks' $\lambda$. Wilks' $\lambda$ is a pooled ratio of error variance to effect plus error variance, and provides an assessment of whether the population mean of the combined dependent variables (test scores in a domain) is similar across the three time points.

In this study, at $\alpha=0.05$, there was adequate power to detect medium and large effect sizes (power ranging from 0.60 to 0.97), but insufficient power to detect small effect sizes (0.14 to 0.22 , depending on statistical test).

To investigate the second issue, namely whether deficits identified previously at three months resolve or improve by 12 months, and whether similarly identified gains are maintained, selected univariate analysis of variances were followed by pairwise comparisons between baseline and 12 months and between 3 and 12 months, using the Bonferroni correction to set comparison-wise $\alpha$ at 0.05 .

\section{RESULTS}

Because baseline to three month comparisons have been reported previously in an overlapping sample, ${ }^{14}$ they are not repeated here.

\section{Tremor rating and stimulation parameter comparisons}

Tremor scores on medication and on stimulation at 12 months were significantly better than those taking drugs at baseline $($ mean $=19.35, \mathrm{SD}=6.85 ; t(39)=12.18, \mathrm{p}<0.001)$. Tremor scores and stimulation parameters did not change significantly between 3 and 12 months (see table 1 ).

\section{Neurocognitive comparisons}

The five Dementia Rating Scale subtest scores combined changed significantly over time (Wilks' $\lambda=0.66, F(10,148)$ $=3.46, \mathrm{p}<0.001)$ and pairwise comparisons showed improvements from baseline to 12 months in Construction scores $(p<0.001)$, and from 3 to 12 months $(p=0.05)$ in Conceptualisation scores.

Change in fine visuomotor coordination (Wilks' $\lambda=0.60, F$ $(4,110)=7.98, \mathrm{p}<0.001)$, related to specific improvement in dominant hand performance $(F(2,56)=15.22, \mathrm{p}<0.001)$, was maintained between baseline and 12 months $(\mathrm{p}<0.01)$. Of the 29 patients who completed the Grooved Pegboard, 28 had operations for dominant side symptoms.

Change in visuoperceptual functioning (Wilks' $\lambda=0.78, F$ $(4,130)=4.30, p<0.01)$ was attributable to Hooper Visual Organization Test (HVOT) score changes $(F(2,66)=7.86$, $\mathrm{p}=0.001)$, and significantly on improvement from baseline to 12 months $(\mathrm{p}<0.01)$.

Verbal memory was also affected by DBS (Wilks' $\lambda=0.56, F$ $(12,126)=3.53, p<0.001)$. Follow up pairwise comparisons of significant univariate results showed significant improvements (all $\mathrm{p}<0.01$ ) from baseline to 12 months in California Verbal Learning Test (CVLT) Immediate Recall, Short-Delay Recall, Long-Delay Recall, and Recognition Hits, and in delayed recall of prose passages (Wechsler Memory ScaleRevised, Logical Memory). CVLT Immediate Recall ( $p=0.01$ ) also improved between 3 and 12 months.

\section{Mood state and quality of life comparisons}

An effect on mood state across assessments was observed (Wilks' $\lambda=0.66, F(16,126)=1.82, \mathrm{p}=0.04)$. The Tension/ Anxiety subscale of the Profile of Mood States (POMS; $F$ $(2,70)=6.89, \mathrm{p}<0.01)$ improved between baseline and 12 months $(\mathrm{p}<0.01$; see table 4$)$.

Table 4 Mood state scores at baseline, three, and 12 months after surgery (mean/SD) and number of patients displaying test score changes of two or more standard deviations from three to 12 months and baseline to 12 months

\begin{tabular}{|c|c|c|c|c|c|c|c|}
\hline & \multirow[b]{3}{*}{ Baseline } & \multirow[b]{3}{*}{$\begin{array}{l}\text { Three months } \\
\text { after surgery }\end{array}$} & \multirow[b]{3}{*}{$\begin{array}{l}\text { Twelve months } \\
\text { after surgery }\end{array}$} & \multirow{2}{*}{\multicolumn{2}{|c|}{$\begin{array}{l}\text { Improvement } \\
>2 \mathrm{SD}\end{array}$}} & \multirow{2}{*}{\multicolumn{2}{|c|}{$\frac{\text { Decline }}{>2 S D}$}} \\
\hline & & & & & & & \\
\hline & & & & $3-12$ & B-12 & 3-12 & B-12 \\
\hline \multicolumn{8}{|l|}{ Mood state $(n=36)$} \\
\hline Beck Depression Inventory $(/ 63)^{*}$ & $6.14(5.00)$ & $5.61(4.72)$ & $5.86(5.00)$ & 0 & 0 & 0 & 0 \\
\hline Beck Anxiety Inventory (/63)* & $8.56(5.84)$ & $7.78(5.56)$ & $8.56(6.43)$ & 0 & 0 & 0 & 0 \\
\hline \multicolumn{8}{|l|}{ Profile of Mood States (t score) } \\
\hline Tension-Anxiety* ‡ & $41.83(5.96)$ & $38.75(5.67)$ & $38.61(6.13)$ & 0 & 0 & 0 & 0 \\
\hline Depression-Dejection* & $36.97(3.67)$ & $37.00(4.16)$ & $37.78(4.76)$ & 0 & 0 & 0 & 0 \\
\hline Anger-Hostility* & $40.31(3.78)$ & $40.61(4.08)$ & $41.19(4.52)$ & 0 & 0 & 0 & 0 \\
\hline Vigor-Activity & $61.00(8.80)$ & $61.00(9.44)$ & $60.50(9.44)$ & 0 & 1 & 0 & 0 \\
\hline Fatigue-Inertia* & $44.89(7.52)$ & $46.17(6.66)$ & $45.92(6.37)$ & 0 & 1 & 0 & 0 \\
\hline Confusion-Bewilderment* ${ }^{*}$ & $40.83(5.10)$ & $39.72(4.39)$ & $40.72(6.43)$ & 0 & 0 & 0 & 0 \\
\hline
\end{tabular}


Table 5 Quality of life at baseline, three, and 12 months after surgery (mean/SD) and number of patients displaying test score changes of two or more standard deviations from three to 12 months and baseline to 12 months

\begin{tabular}{|c|c|c|c|c|c|c|c|}
\hline & \multirow[b]{3}{*}{ Baseline } & \multirow{3}{*}{$\begin{array}{l}\text { Three months } \\
\text { after surgery }\end{array}$} & \multirow{3}{*}{$\begin{array}{l}\text { Twleve months } \\
\text { after surgery }\end{array}$} & \multirow{2}{*}{\multicolumn{2}{|c|}{$\begin{array}{l}\text { Improvement } \\
>2 \mathrm{SD}\end{array}$}} & \multirow{2}{*}{\multicolumn{2}{|c|}{$\frac{\text { Decline }}{>2 \mathrm{SD}}$}} \\
\hline & & & & & & & \\
\hline & & & & $3-12$ & B-12 & $3-12$ & B-12 \\
\hline \multicolumn{8}{|l|}{ Quality of life ( $n=29)$} \\
\hline \multicolumn{8}{|l|}{ Sickness Impact Profile (\%)* } \\
\hline Physical & $4.63(5.11)$ & $5.02(6.68)$ & $7.73(12.01)$ & 0 & 0 & 2 & 3 \\
\hline Psychosocial $^{\dagger}$ & $8.59(5.97)$ & $4.95(6.76)$ & $6.37(8.46)$ & 1 & 1 & 2 & 1 \\
\hline Overall & $7.95(4.80)$ & $6.13(6.41)$ & $7.82(9.92)$ & 1 & 0 & 2 & 2 \\
\hline \multicolumn{8}{|c|}{ Modified Parkinson's Disease Questionnaire $(\%)^{*}$} \\
\hline Mobility & $20.03(19.62)$ & $17.66(23.80)$ & $21.55(25.02)$ & 0 & 0 & 0 & 0 \\
\hline Activities of Daily Living ${ }^{\dagger}$ & $48.55(15.84)$ & $21.59(20.75)$ & $27.38(27.69)$ & 0 & 2 & 1 & 0 \\
\hline Emotional well being ${ }^{\dagger} \ddagger$ & $23.90(15.02)$ & $9.55(11.42)$ & $14.38(13.53)$ & 0 & 0 & 0 & 0 \\
\hline Stigma ${ }^{\dagger \ddagger}$ & $35.69(27.32)$ & $11.93(20.46)$ & $16.28(19.13)$ & 1 & 3 & 0 & 0 \\
\hline Social support & $9.52(13.69)$ & $4.76(9.44)$ & $7.72(13.32)$ & 0 & 0 & 0 & 0 \\
\hline Cognition & $18.45(15.72)$ & 17.79 (17.54) & $18.28(14.55)$ & 1 & 0 & 0 & 0 \\
\hline Communication $^{\dagger}$ & $21.03(25.06)$ & $10.90(19.24)$ & $13.24(15.33)$ & 1 & 1 & 0 & 0 \\
\hline Bodily discomfort & $15.79(15.03)$ & $18.07(19.10)$ & $19.83(20.48)$ & 1 & 1 & 0 & 1 \\
\hline
\end{tabular}

Significance of the QoL multivariate analysis of variance (Wilks' $\lambda=0.29, F(22,92)=3.64, \mathrm{p}<0.001$ ) was attributable to improvement in the Activities of Daily Living $(F(2,56)$ $=26.89, \mathrm{p}<0.001)$, Emotional Well-Being $(F(2,56)=15.15$, $\mathrm{p}<0.001)$, Stigma $(F(2,56)=11.25, \mathrm{p}<0.001)$, and Communication $(F(2,56)=4.44, \mathrm{p}=0.02)$ subscales of the mPDQ. Post hoc comparisons revealed significant improvements in scores from baseline to 12 months for Activities of Daily Living $(\mathrm{p}<0.001)$, Emotional Well Being $(\mathrm{p}<0.01)$, and Stigma $(\mathrm{p}<0.01$; see table 5$)$.

\section{Frequency of score changes}

Previously identified changes in verbal fluency tended to persist-between baseline and three months, $7.5 \%$ of patients showed decline on semantic verbal fluency, and at 12 months, $10 \%$ of the patients had significantly lower scores than at baseline.

\section{DISCUSSION}

Only two studies ${ }^{12}{ }^{14}$ have examined short-term neurobehavioural outcomes after thalamic DBS for ET, and together they suggest that QoL improves significantly while cognitive morbidity is comparatively minimal. The aims of this study were to evaluate changes in cognition, mood state, and QoL associated with unilateral thalamic DBS in ET, and to determine durability of these changes over 12 months. With regard to cognitive performance, scores on a cognitive screening measure (DRS) improved over the course of the three assessments. Improvements over time were similarly observed in tasks of fine visuomotor coordination (dominant hand only) (Grooved Pegboard), visuoperceptual gestalt formation (HVOT), and verbal memory (immediate and delayed recall and recognition of a word list; CVLT). Of note, the gains observed on these tests at three month follow up were still evident at 12 months, but few new gains occurred during the 3 to 12 month interval (with the exception of further increases in DRS Conceptualisation and CVLT Immediate recall scores). Although no new significant losses in any cognitive function occurred as indexed by average scores, it is noteworthy that by 12 months, relative to pre-surgical baseline, $10 \%$ of patients ( 4 of 40), showed declines also in semantic verbal fluency. Compared with baseline, lexical verbal fluency remained mildly diminished. Overall, cognitive test results suggest that circumscribed verbal fluency declines accompany unilateral thalamic DBS in ET. Most cognitive functions assessed do not change appreciably, however, and, together with isolated possible improvements in memory, support the contention that thalamic DBS in ET is safe from a cognitive standpoint.
Despite being very limited in scope and of modest clinical significance, the neurobehavioural changes observed require further study so that the underlying physiological and cognitive mechanisms might be better understood. Whether the observed cognitive changes are related to disease progression cannot be determined, as no data regarding neuropsychological changes over time in non-surgical ET patients have been reported. Also, given that patients were evaluated on measures of cognition and mood after surgery only with the stimulator on, you cannot from present data unambiguously attribute verbal fluency decrements to stimulation rather than a microthalamotomy effect. Given studies showing that in PD the effects of thalamic stimulation on language and memory vary as a function of stimulation parameters (see Hugdahl and Wester, ${ }^{21}$ Johnson and Ojemann, ${ }^{22}$ Pillon et al, ${ }^{23}$ and Tröster et $\left.a^{24}\right)$, and the fact that the lexical verbal fluency decrement persists to 12 months (and are accompanied by clinically notable declines in semantic fluency in about $10 \%$ of patients), enthusiasm for a microthalamotomy effect explanation is diminished. Indeed, stimulation of subcortical structures has been shown to affect both motor speech ${ }^{25}$ and cognitive processes $^{26}{ }^{27}$ involved in verbal fluency task performance, making it more likely that changes in fluency are attributable to stimulation in itself. Notwithstanding intraoperative recording and stimulation for localisation purposes, the absence of radiological verification of electrode location in this and other studies limits statements about the neuroanatomic parameters of stimulation effects on cognition.

Another important question concerning the declines in verbal fluency is their predictability; in other words, can you confidently identify people at risk for such declines before surgery? Present data do not permit that this issue is investigated directly, but some preliminary observations to direct future studies are in order. When comparing the group of patients who had baseline lexical fluency scores below average to those patients with scores average and above, only the first group showed a decline in semantic fluency. It is postulated that this occurrence may be related to frontal/executive components of lexical fluency, because baseline semantic fluency scores for the groups were comparable. Given that subtle and circumscribed executive deficits have been observed in ET, ${ }_{67}$ and that executive deficits present a risk for post-DBS cognitive decline in $\mathrm{PD}_{1}{ }^{28}$ the possibility arises that $\mathrm{ET}$ and $\mathrm{PD}$ share predictors of post-DBS cognitive declines. As a matter of interest, relative to other factors possibly contributing to cognitive decline, neither of the two patients with a diagnosis of both PD and ET, nor the one later given topiramate (which might adversely affect cognition ${ }^{29}{ }^{30}$ ) were among the four whose semantic fluency declined postoperatively. 
Interpretation of gains in test scores is also complicated by the possibility that practice effects, rather than true improvements in cognitive function, account for these positive changes. That practice effects might be the source of observed gains on cognitive tests cannot be excluded with confidence (particularly because there is no test-retest reliability data available for ET), but three observations are noteworthy in this regard. Firstly, the gain observed in the total number of words recalled on trials 1-5 of the CVLT (Immediate Recall) is greater than that expected from repeated test exposure alone per normative data. ${ }^{31}$ Secondly, the most substantial gain occurred at the third assessment (after a nine month test-retest interval) rather than at the second assessment (four month interval). This is not consistent with a practice effect because test-retest gain bears an inverse relation to test-retest interval. ${ }^{32}$ Thirdly, the partial $\eta^{2}$ effect sizes were generally large, ranging from 0.20 to 0.35 on cognitive measures.

Results of this study suggest that, similar to neuropsychological test score changes, changes in mood state and QoL scores are also stable over the first 12 postoperative months. Profile of Mood States reveals continued statistically significant reduction in tension and anxiety symptoms at 12 months, but the BAI does not reveal this, probably because the instruments measure different aspects of anxiety (see Higginson $e a^{33}{ }^{34}$ ). It is unlikely that the reduction in anxiety postoperatively is simply attributable to elimination of possible anticipatory anxiety associated with upcoming surgery, because patients who were taking anxiolytics at baseline were also taking them 12 months after surgery, and the two patients who withdrew them three months after surgery had them reinstated again by 12 months after surgery.

Consistent with our earlier findings, a disease specific QoL measure (mPDQ) reveals that after DBS, patients are more satisfied with activities of daily living, emotional wellbeing, and perceived stigma. Although subtle declines in satisfaction with these three QoL domains seem to occur between three and 12 months, the decline is not significant, and the improvement relative to baseline remains statistically significant. Whether this subtle decline in QoL represents a loss of an initial postoperative "honeymoon effect," dynamic adjustment over time of patient expectations based on new "realities,",35 operation of new physical and psychosocial factors not measured here that adversely impact QoL, or a shift in the valence attached by patients to certain aspects of QoL, is uncertain. It is fairly certain, however, that this subtle reduction in QoL satisfaction does not represent diminution of tremor control over time, given that neither tremor ratings, nor stimulation parameters, changed significantly between three and 12 months.

The SIP, a generic QoL measure, reveals statistically significant change overall (that is, across the three assessments and the three domains-Total, Physical, Psychosocialconsidered in tandem), but significant changes in specific scores between pairs of time intervals are lacking (with the exception of a significant improvement in psychosocial aspects of QoL between baseline and three months). The somewhat discordant findings rendered by the MPDQ and SIP invite comment but are not difficult to reconcile. SIP scores in the group of patients studied here reveal a floor effect (consistent with observations made previously ${ }^{14}$ ), thus lending credence to the oft made criticism that generic QoL measures tend not to be sensitive to specific changes most central to a given disease or syndrome. Particularly salient is the apparent insensitivity of the SIP Physical scale to tremor improvement. Despite the fact that the tremor rating revealed continued, significant improvement at 12 months relative to baseline (and tremor scores and stimulation parameters remained comparable at three and 12 month follow up), the average SIP Physical function scale was not significantly better at 12 months than preoperatively. Moreover, while the subtle decline in SIP Physical score between three and 12 months was not statistically significant,
$10 \%$ ( 3 of 29) of the patients who completed the questionnaire showed declines in this score of two or more standard deviations. A probable reason for the insensitivity of the SIP Physical scale to effects of tremor is the fact that the tremor rating focuses on upper extremity tremor. In contrast, the Physical scale of the SIP includes mainly items relating to mobility, ambulation, and body care and movement, activities that are minimally affected by tremor of the upper extremities.

In summary, thalamic DBS appears safe from a cognitive standpoint. Isolated gains may be noted in verbal memory, while circumscribed decrements in verbal fluency occur. Unilateral thalamic DBS in ET is also associated with improvements in anxiety and sizable improvements in several domains of QoL. These changes seem comparatively stable across a 12 month postoperative interval, although some dampening of the QoL gains may occur. Review of results across individual patients suggests some heterogeneity in outcome, and the hypothesis is raised that pre-existing executive dysfunction, and more specifically, impoverished lexical/ phonemic verbal fluency, heralds post-surgical declines in verbal fluency.

\section{Authors' affiliations}

J Fields, A I Tröster, S P Woods, Department of Psychiatry and Behavioral Sciences, University of Washington School of Medicine, Seattle, USA

A I Tröster, Department of Neurological Surgery, University of Washington School of Medicine

C I Higginson, Center for Neuroscience, University of California, Davis, USA

S B Wilkinson, Department of Neurosurgery, University of Kansas Medical Center, Kansas City, USA

K E Lyons, W C Koller, Department of Neurology, University of Miami School of Medicine, Miami, USA

R Pahwa, Department of Neurology, University of Kansas Medical Center

Competing Interests: Dr Tröster has been a paid consultant for Medtronic, Inc. Dr Pahwa has been reimbursed for speaking and providing consultation, as well as being a recipient of a research grant, from Medtronic, Inc.

\section{REFERENCES}

1 Elble R, Koller WC. The diagnosis and pathophysiology of essentia tremor. In: Tremor. Baltimore: John Hopkins University Press, 1990.

2 Findley LJ. Epidemiology and genetics of essential tremor. Neurology 2000;54 (suppl 4):S8-13

3 Lücking $\mathrm{CH}$, Köster B, Guschlbauer B, et al. Parkinsonian and essential tremors: different entities or different manifestations of the same disorder? Adv Neurol 1999:80:335-9.

4 Gasparini $M$, Bonifati V, Fabrizio E, et al. Frontal lobe dysfunction in essential tremor: a preliminary study. J Neurol 2001;248:399-402.

5 Lacritz LH, Dewey R Jr, Giller C, et al. Cognitive functioning in individuals with "benign" essential tremor. J Int Neuropsychol Soc 2002;8:125-9.

6 Lombardi WJ, Woolston DJ, Roberts JW, et al. Cognitive deficits in patients with essential tremor. Neurology 2001;57:785-90.

7 Tröster AI, Woods SP, Fields JA, et al. Neuropsychological deficits in essential tremor: an expression of cerebello-thalamo-cortical pathophysiology? Eur J Neurol 2002:9:143-51.

8 Caparros-Lefebvre D, Blond S, Pécheux N, et al. Evaluation neuropsychologique avant et après stimulation thalamique chez 9 parkinsoniens. Rev Neurol 1992;148:1 17-22.

9 Straits-Tröster K, Fields JA, Wilkinson SB, et al. Health-related quality of life in Parkinson's disease after pallidotomy and deep brain stimulation. Brain Cogn 2000;42:399-416.

10 Tröster Al, Fields JA, Wilkinson SB, et al. Neuropsychological functioning before and after unilateral thalamic stimulating electrode implantation in Parkinson's disease. [Electronic manuscript]. Neurosurg Focus 1997; 2: article 9.

11 Woods SP, Fields JA, Lyons KE, et al. Neuropsychological and quality of life changes following unilateral thalamic deep brain stimulation in Parkinson's disease: a 12 -month follow-up. Acta Neurochir $2001 ; 143: 1273-8$

12 Lucas JA, Rippeth JD, Uitti RJ, et al. Neuropsychological functioning in a patient with essential tremor with and without bilateral VIM stimulation. Brain Cogn 2000;42:253-67

13 Blond S, Caparros-Lefebvre D, Parker F, et al. Control of tremor and involuntary movement disorders by chronic stereotactic stimulation of the ventral intermediate thalamic nucleus. J Neurosurg 1992;77: $62-8$. 
14 Tröster Al, Fields JA, Pahwa R, et al. Neuropsychological and quality of life outcome after thalamic stimulation for essential tremor. Neurology 1999;53:1774-80.

15 Beijani BP, Damier P, Arnulf I, et al. Transient acute depression induced by high-frequency deep-brain stimulation. $N$ Engl J Med 1999;340: 1476-80

16 Gálvez-Jiménez $\mathbf{N}$, Hargreave $M$. Topiramate and essential tremor. Ann Neurol 2000;47:837-8.

17 Koller WC, Hristova A, Brin M. Pharmacologic treatment of essential tremor. Neurology 2000;54 (suppl 4):S30-8

18 Fahn S, Tolosa E, Marin C. Clinical rating scale for tremor. In: Jankovic J, Tolosa E, ed. Parkinson's disease and movement disorders. Baltimore: Williams and Wilkins, 1988:225-34.

19 Hubble JP, Busenbark KL, Wilkinson S, et al. Deep brain stimulation for essential tremor. Neurology 1996;46:1150-3.

20 Koller W, Pahwa R, Busenbark K, et al. High-frequency unilateral thalamic stimulation in the treatment of essential and parkinsonian tremor. Ann Neurol 1997;42:292-9.

21 Hugdahl K, Wester K. Lateralized thalamic stimulation: effects on verbal memory. Neuropsychiatry Neuropsychol Behav Neurol 1997;10: 155-61

22 Johnson MD, Ojemann GA. The role of the human thalamus in language and memory: evidence from electrophysiological studies. Brain Cogn 2000;42:218-30

23 Pillon B, Ardouin C, Damier P, et al. Neuropsychological changes between "off" and "on" STN or GPi stimulation in Parkinson's disease. Neurology 2000;55:411-18.
24 Tröster Al, Wilkinson SB, Fields JA et al. Chronic electrical stimulation of the left ventrointermediate (Vim) thalamic nucleus for the treatment of pharmacotherapy-resistant Parkinson's disease: a differential impact on access to semantic and episodic memory? Brain Cogn 1998;38:125-49. 25 Murdoch BE. Subcortical brain mechanisms in speech and language. Folia Phoniatr Logop 2001;53:233-51.

26 Saint-Cyr JA, Trépanier LL, Kumar R, et al. Neuropsychological consequences of chronic bilateral stimulation of the subthalamic nucleus in Parkinson's disease. Brain 2000;1 23:2091-108.

27 Woods SP, Fields JA, Tröster Al. Neuropsychological sequelae of subthalamic nucleus deep brain stimulation in Parkinson's disease: a critical review. Neuropsychol Rev 2002;12:11 1-26.

28 Pollak P, Benabid A-L, Krack P, et al. Deep brain stimulation. In Jankovic J, Tolosa E, eds. Parkinson's disease and movement disorders. 3rd edn. Baltimore: Williams and Wilkins, 1998:1085-101.

29 Meador KJ. Effects of topiramate on cognition. $J$ Neurol Neurosurg Psychiatry 2001;71:134-35.

30 Thompson PJ, Baxendale SA, Duncan JS, et al. Effects of topiramate on cognitive function. J Neurol Neurosurg Psychiatry 2000;69:636-41.

1 Delis DC, Kramer JH, Kaplan E, et al. California verbal learning rest-adult version. San Antonio: The Psychological Corporation, 1987

32 Sattler JM, edr. Assessment of children: cognitive applications. 4th edn. La Mesa, CA: Jerome M Sattler, 2001.

33 Higginson Cl, Fields JA, Koller WC, et al. Questionnaire assessment potentially overestimates anxiety in Parkinson's disease. J Clin Psycho Med Set 2001;8:95-9.

34 Higginson $\mathrm{Cl}$, Fields JA, Tröster Al. Which symptoms of anxiety diminish after surgical interventions for Parkinson's disease. Neuropsychiatry Neuropsychol Behav Neurol 2001;14:117-21.

35 Schwartz CE, Sprangers MAG, eds. Adaptation to changing health response shift in quality-of-life research. Washington, DC: American Psychological Association, 2000

\section{New JNNP online submission and review system}

The Editors of JNNP are pleased to inform authors and reviewers of its new online submission and review system. Bench>Press is a fully integrated electronic system which uses the internet to allow rapid and efficient submission of manuscripts, plus the entire peer review process to be conducted online.

Authors can submit their manuscript in any standard word processing software. Graphic formats acceptable are: .jpg, .tiff, .gif, and eps. Text and graphic files are automatically converted to PDF for ease of distribution and reviewing purposes. Authors are asked to approve their submission before it formally enters the reviewing process.

To access the system click on "SUBMIT YOUR MANUSCRIPT HERE" on the JNNP homepage: http://www.jnnpinl.com/, or you can access Bench>Press directly at http:// submit-jnnp.bmijournals.com/.

We are very excited with this new development and we would encourage authors and reviewers to use the on-line system where possible. It really is simple to use and should be a big improvement on the current peer review process. Full instructions can be found on Bench>Press http://submit-jnnp.bmijournals.com/, and JNNP online at http://www. innpjnl.com/. Please contact Natalie Davies, Project Manager, ndavies@bmjgroup.com for further information.

\section{PRE-REGISTER WITH THE SYSTEM}

We would be grateful if all JNNP authors and reviewers pre-registered with the system. This will give you the opportunity to update your contact and expertise data, allowing us to provide you with a more efficient service.

Instructions for registering

1. Enter http://submit-jnnp.bmijournals.com

2. Click on "Create a New Account" in the upper left hand side of the Bench>Press

homepage

3. Enter your email address in the space provided.

4. Please be sure to enter the email address that you received this email message at.

You will be given the opportunity to change this once you have created an account.

5. Choose a password for yourself and enter it in the spaces provided.

6. Complete the question of your choice to be used in the event you cannot remember your password at a later time.

7. Click on the "Save" button at the bottom of the screen.

8. Check the e-mail account you registered under. An email will be sent to you with a verification number and URL.

9. Once you receive this verification number, click on the URL hyperlink and enter

the verification number in the relevant field. This is for security reasons and to

check that your account is not being used fraudulently.

10. Enter/amend your contact information, and update your expertise data. 